\title{
Visões brasileiras do exterior
}

GUIMARÃES, Samuel Pinheiro (org.). Argentina: visões brasileiras (308 p.); Alemanha: visões brasileiras (368 p.); Estados Unidos: visões brasileiras (264 p.); África do Sul: visões brasileiras (322 p.). Brasília: Instituto de Pesquisa de Relações Internacionais, Fundação Alexandre de Gusmão, 2000.

A obra organizada pelo Diretor do Instituto de Pesquisa de Relações Internacionais do Itamaraty compreende quatro volumes de textos de autores e pesquisadores brasileiros de destaque no âmbito político, diplomático e acadêmico. A coleção teve dois objetivos: em primeiro lugar, aumentar no Brasil o conhecimento acerca das relações internacionais de seus principais parceiros e, em segundo lugar, estimular estudos sobre outros países importantes. E uma abordagem: desenvolver análises das relações internacionais desses países sob o ângulo diplomático, político, econômico e estratégico, mas numa ótica de interpretação desde a perspectiva brasileira. Embora a obra apresente uma análise sincronizada e evolutiva desde a década de 1940 à atualidade, a ênfase foi posta na conjuntura recente, a década de 1990.

Os colaboradores foram, para o estudo da Argentina: Amado Luiz Cervo (A política exterior da Argentina: 1945-2000); Pedro Motta Pinto Coelho (Observações sobre a visão argentina da política internacional de 1945 até hoje); Ricardo Markwald e Roberto Iglesias (A política externa econômica da Argentina: uma visão dos anos 90). Para o estudo dos

Estados Unidos: Cesar Guimarães (Envolvimento e ampliação: a política externa dos Estados Unidos); José Tavares de Araújo (A política econômica externa dos Estados Unidos nos anos 90); Mauro Mendes de Azeredo (Visão americana da política internacional de 45 até hoje). Para o estudo da Alemanha: Amaury Banhos Porto de Oliveira (A questão alemã desgasta a paz americana); Luiz Alberto Moniz Bandeira (A política exterior da Alemanha); Theotônio dos Santos (A política econômica externa da Alemanha). Para o estudo da África do Sul: Hélio Magalhães de Mendonça (Política externa da África do Sul (1945-1999); Luiz Henrique Nunes Bahia (A política Externa da África do Sul: da internacionalização à globalização); Paul Israel Singer (A política econômica externa da África do Sul).

Esses estudos foram debatidos em seminários realizados no Rio de Janeiro e em São Paulo, com a participação de especialistas que agregaram novas reflexões sobre os temas.

$\mathrm{O}$ volume dedicado à Argentina reúne três textos que esboçam visões acerca da evolução da política externa argentina, desde a depressão capitalista e a 
II Guerra Mundial até o fim do milênio. No primeiro texto, Cervo aborda as tendências históricas das últimas décadas, o revisionismo dos anos 1990 e, com maior enfoque, os objetivos e resultados da política exterior do governo de Carlos Saúl Menem, entre 1989 e 1999.

A Terceira Posição (1945-1955), rótulo da fase crítica da política internacional argentina durante a Guerra Fria, observada no primeiro governo peronista, foi marcada por indefinições no posicionamento ante à política internacional do sistema bipolar. Um cenário externo de grande tensão, marcado por batalhas políticas entre duas superpotências, a URSS e os EUA. Tal cenário criou por longo período junto à Argentina a expectativa de uma nova ordem mundial. Cervo critica o revisionismo histórico argentino dos anos 1990 que insiste numa análise negativa das décadas que se estendem de 1930-45 a 1983-89. O problema objeto de análise nesse período conduz às possibilidades de inserção ou isolamento da Argentina no contexto internacional.

O ponto mais atraente na literatura de Cervo é, sem dúvida, a análise atualizada da reincorporação da Argentina ao Primeiro Mundo. O autor elenca quatro categorias de motivações na origem da política exterior do Governo de Menem. Em linhas gerais, a idéia principal de cada categoria é: a decadência nacional geradora de autocompaixão; o realismo periférico; a recompensa econômica pelo alinhamento político; e a ótica condescendente dos frutos da globalização para a economia argentina.(p.77)

O organizador dá continuidade à obra agregando textos do diplomata Pedro Motta e dos economistas Ricardo Markwald e Roberto Iglesias, que conduzem uma análise da evolução do pensamento político-econômico da Argentina e, em alguns momentos, inserem contextos da política brasileira. Partindo das origens do comércio exterior argentino à problemática dos principais tratados e dos atuais blocos econômicos, os autores polemizam, em particular, a herança Mercosul, como um legado controvertido do governo Alfonsín para a gestão de Menem.

O segundo volume, que enfoca as visões brasileiras da Alemanha, apresenta, inicialmente, um texto do embaixador Amaury Oliveira relacionando a evolução político-econômica da Alemanha com a volubilidade da Pax Americana. O texto desenvolve análises que vão do surgimento da "Questão alemã”, em 1871, quando da consolidação da Alemanha como um Estado nacional, ao Pós-Segunda Guerra Mundial. Além disso, o autor coteja as depressões vividas pela RFA com a extraordinária capacidade de reconstrução diante das transformações da política econômica internacional. $\mathrm{O}$ autor aborda com entusiasmo a visão de mudança na política alemã: "O capitalismo alemão não perdeu sua singularidade no quadro das várias formas de capitalismo que concorrem entre si no mundo, e sobretudo mantém intacta sua capacidade transformativa." (p.116). Por fim, uma abordagem sobre a Alemanha unificada, que vem exercendo papel decisivo na comunidade européia. 
O organizador dá prosseguimento à obra, reunindo reflexões rebuscadas do cientista político Moniz Bandeira, que discorre sobre questões referentes à política exterior da Alemanha no período 1949-1999. O texto polemiza desde a inserção da RFA na Aliança Atlântica e seu rearmamento, até as transformações que levaram-na à reunificação. Moniz, de forma contundente, descreve uma Alemanha preocupada com os riscos de manter sua segurança social, diante de seu enquadramento como potência econômica internacional.

Os textos encerram o tema com uma abordagem econômica externa da Alemanha no período de 1945 à 1999. Nesse contexto, o autor apresenta um enfoque exaustivo da política exterior dos anos 90, agregando informações econômicas enriquecidas com dados estatísticos e interessantes análises macro-econômicas e da economia internacional.

A historicidade contida no volume dedicado à África do Sul passa por questões que abordam contextos de capital importância para se revisitar a humanidade, como a independência da União Sul-Africana em 1910, sob o regime westminsteriano, responsável pela integração dos povos britânicos e bôeres, com longo período de ditadura racista, no qual era furtado aos negros o direito de representação política.

Nas palavras do diplomata Helio Mendonça, "não cabe neste trabalho uma história do apartheid ou o exame da filosofia que o embasava...", mas uma análise da "questão da identidade nacional" (p.13). Helio discute com envolvimento a questão do isolamento da África do Sul no contexto da comunidade internacional até o processo que inicia seu rompimento.

Deste ponto, os textos desenvolvem uma análise macro-histórica da África do Sul, que se inicia com o período do Partido Unido, intensificado com a criação da Organização das Nações Unidas - ONU. Esta se vê forçada a defender questões de seu papel básico de mediador dos direitos humanos, tais como: a situação legal do Sudoeste Africano e o tratamento segregacionista dos imigrantes indianos. $\mathrm{O}$ apartheid é discutido pela primeira vez na ONU em 1952, quando a comunidade internacional demonstra seu repúdio e sua resistência ao tratamento dado ao Sudoeste Africano e aos indianos.

Podemos constatar uma visão bastante atual e singular, no âmbito acadêmico, do tratamento que o autor dedica ao renascimento da política econômica externa pós-apartheid. Os desenlaces que decorrem na década de 90 atraem a atenção do leitor com análises importantes para entender melhor as origens que marcaram o fim desse abominável regime. Tais origens tiveram como fatores exógenos à política doméstica da África: as pressões internacionais pelos direitos humanos, bem como os movimentos pela paz internacional e pelo Estado democrático. Esses fatores foram, segundo o cientista político Luiz Bahia, decisivos para inserir a África nos negócios mundiais, associados a planos de desenvolvimento por meio de cooperação regional e internacional de interdependências econômicas. 
Por fim, o organizador encerra a obra Visões Brasileiras sob o signo dos Estados Unidos da América. Os textos, que propõem motes tradicionais de discussão da história contemporânea das relações internacionais, como o posicionamento político dos Estados Unidos no contexto de sua ampliação econômica no cenário internacional, examinam cenários similares de temporalidade histórica. Inicialmente, partem da análise do cientista político César Guimarães, que flexibiliza uma discussão sobre os desfechos da economia dos Estados Unidos desde o pós-Segunda Guerra Mundial e o reodernamento político da Guerra Fria, na busca do comprometimento de outras nações com o alinhamento a seus interesses político-econômicos, até o atual cenário da política externa do liberalismo estadunidense.

$\mathrm{Na}$ proposta do organizador, os textos se conformam com a cronologia que parte dos anos 1940 e se estende ao novo milênio. Mas o autor aprofunda o período que sucede ao enfraquecimento da URSS e à unificação alemã. Com o desaparecimento da URSS, os Estados Unidos passam a ser a única superpotência do mundo. Entretanto, o foco principal continua sendo o contexto atualizado, no qual o consultor internacional José Araújo implementa com habilidade uma análise da política econômica externa dos Estados Unidos nos anos 90.

As reflexões sobre a globalização e os interesses particulares dos EUA são expostas nessa obra, e perpassam a problemática política do comércio exterior e da unificação européia. A obra encerra com um texto do diplomata e escritor Mauro Azeredo, propondo novas reflexões sobre a gestão da política internacional dos Estados Unidos para com o resto do mundo.

Os quatros volumes de Visões Brasileiras oferecem ao leitor um valioso estudo contemporâneo sobre a política externa de países que serviram de cenário para as diversas reflexões sobre a história das relações internacionais do Brasil e do mundo. Há de se tecer loas a um aspecto singular desta obra: a preocupação de se vislumbrar a necessidade diuturna de revisitar a história, como condição única do pesquisador não incorrer em anacronismos.

A visão inovadora dos seletos brasileiros dá à obra um caráter particular e, ao mesmo tempo, harmônico, do ponto de vista da temporalidade histórica. A obra guarda uma singularidade na organização dos textos, oferecendo ao leitor subsídios históricos para enredar-se no tema. Destarte, a organização dos textos passa pelo período que se estende da década de 1940 até o final dos anos 1980, como uma espécie de embasamento acadêmico. Em seguida, traz à luz dos debates o foco principal: as reflexões acerca da política externa e das relações econômicas dos anos 1990. Com certeza, trata-se de uma obra de grandes pretensões intelectuais. 